\title{
ANABOLISMO PÓS-EXERCÍCIO: INFLUÊNCIA DO CONSUMO DE CARBOIDRATOS E PROTEÍNAS
}

Daniele Preto Kater, Aline Beatriz Pires, Manoel Carlos Spiguel Lima, Jair Rodrigues Garcia Júnior

Curso de Educação Física da UNOESTE, Presidente Prudente, SP

\section{RESUMO}

O exercício físico provoca alterações no metabolismo, aumentando a taxa de catabolismo em comparação à taxa de anabolismo, em razão da necessidade de mobilização dos combustíveis energéticos para utilização pelos músculos durante o esforço. Ao final do esforço, durante a recuperação, o catabolismo pode continuar predominando, mas é possível intervir com o consumo de alimentos, o que influencia a secreção hormonal e estimula o anabolismo. Apesar de haver estudos sobre a ingestão de carboidratos e proteínas após exercícios físicos em geral, não há ainda consenso sobre qual nutriente é mais importante para a repleção dos substratos energéticos e síntese protéica, que proporcionam a recuperação dos tecidos e restauração da capacidade para realização de uma nova sessão de treinamento. Nesse sentido, este estudo teve como objetivo revisar, descrever, comparar e discutir as alterações fisiológicas decorrentes do catabolismo e anabolismo durante a recuperação de uma sessão de treinamento resistido seguida pelo consumo de carboidratos e proteínas. Foi realizado levantamento dos artigos nas bases de indexação, priorizando aqueles publicados a partir de 2002. O consumo de carboidratos e proteínas pós-exercício estimula o anabolismo de forma eficiente, sendo a quantidade de carboidratos e proteínas um dos fatores determinantes para proporcionar um ambiente hormonal favorável para os processos de repleção do glicogênio e síntese protéica. Foi constatado que a concentração de insulina desempenha papel chave no processo anabólico pós-exercício. Outros estudos com diferentes combinações e quantidades de nutrientes e avaliação direta dos processos de repleção do glicogênio e síntese protéica são necessários.

Palavras-chave: Exercício resistido, anabolismo, recuperação, carboidrato, insulina, glicogênio.

\section{POST EXERCISE ANABOLISM: INFLUENCE OF CARBOHYDRATE AND PROTEIN INTAKE}

\begin{abstract}
Physical exercises promote meaningful alterations in the metabolism, raising the catabolism rates compared to the anabolic ones, because the necessity to mobilization of the energetic substrate used by the muscles during the effort. At the end of the effort, during the recovery, the catabolism may continue predominant, but it is possible to interfere by food intake, which influences the hormonal secretion and stimulate anabolism. In spite of having lots of studies about carbohydrate and protein intake post general physical exercise, there is not a consensus about which nutrient is more important for the energy substrates replenishment and protein synthesis, that provide tissues' recovery and restoration of the capacity for a new exercise session. The purpose of this study was to review, describe, compare and discuss the physiological changes resulting from catabolism and anabolism during recovery from a resistance training session followed by carbohydrate and protein intake. It was carried out a search by papers on index basis, selecting mainly these ones published after 2002. The carbohydrate and protein intake post exercise stimulate the anabolismo, being the amount of carbohydrate and protein one aspect, among others, that provide a favorable hormonal environment to glycogen replenishment and protein synthesis. It was noted that insulin concentration plays a key role on anabolic process post exercise. It is necessary others studies with different nutrients and direct analysis of glycogen replenishment and protein synthesis.
\end{abstract}

Keywords: resistance exercise, anabolism, recovery, carbohydrate, insulin, glycogen. 


\section{INTRODUÇÃO}

O exercício físico é um potente agente estressor e, como tal, provoca significativas alterações no metabolismo (COYLE, 2000). De modo geral, ele aumenta a proporção do catabolismo (degradação) em comparação ao anabolismo (síntese), porque há demanda significativamente aumentada em relação aos combustíveis energéticos para sustentação do esforço. Os sistemas nervoso e endócrino controlam as reações de degradação e síntese, mas são possíveis alguns tipos de intervenções externas como o consumo de alimentos, por exemplo, para minimizar o catabolismo.

Devido à ativação do sistema nervoso autônomo, aumento da concentração de hormônios como as catecolaminas e cortisol e ao déficit de oxigênio, a taxa metabólica continua aumentada e em decréscimo gradativo ao final do exercício (AL MULLA et al., 2000). Em conseqüência, a proporção de catabolismo segue um padrão semelhante.

Carboidratos, gorduras e proteínas fornecem a energia necessária para manter as funções corporais em repouso e no esforço. Além disso, são importantes para manutenção e síntese/restauração de estruturas e moléculas bioativas. Durante o exercício, a intensidade e a duração do esforço, a aptidão e o estado nutricional são determinantes da utilização dos substratos energéticos.

O exercício de resistência provoca significativos aumentos nas concentrações de hormônios como testosterona, hormônio do crescimento (GH) e cortisol (SMILIOS et al., 2002). Esse último é essencialmente catabólico e tem predominância durante o exercício, enquanto os dois primeiros estimulam o anabolismo no período de recuperação. O efeito agudo destas alterações é o aumento das interações hormônioreceptor nas células musculares e o efeito crônico, resultante do treinamento, é o aumento do número de receptores e da síntese de proteínas musculares (SMILIOS et al., 2002). Suplementos de carboidratos e proteínas podem ajudar na melhora do desempenho e na síntese protéica muscular (RAMUSSEN et al., 2000; WOLFE, 2000; LAMBERT et al., 2004).

Neste estudo, tivemos por objetivo revisar, descrever, comparar e discutir as alterações fisiológicas decorrentes do catabolismo e anabolismo durante a recuperação de uma sessão de treinamento resistido seguida pelo consumo de carboidratos e proteínas.

\section{MÉTODOS}

A partir das palavras chave exercício resistido, músculo, anabolismo, catabolismo, hormônios, carboidratos, proteínas, aminoácidos, suplementos, glicogênio e recuperação, assim como os termos equivalentes em inglês, foi realizado o levantamento dos artigos nas bases de indexação MedLine, SciELO e Lilacs, priorizando aqueles publicados de 2002 a 2011. As informações foram analisadas, descritas, comparadas e discutidas.

\section{Mobilização e reposição do glicogênio}

Os carboidratos estocados na forma de glicogênio muscular e hepático e a glicose sangüínea são utilizados pelos músculos como fonte primária de combustível durante exercícios aeróbicos e anaeróbicos. Como a produção de energia a partir do glicogênio pode ocorrer na ausência de oxigênio, o glicogênio muscular constitui o principal fornecedor de energia nos primeiros minutos do exercício, quando a utilização de oxigênio não satisfaz as demandas metabólicas (McARDLE et al., 2011).

Durante exercício extenuante, fatores neuro-humorais elevam a produção de catecolaminas, de cortisol e de glucagon e reduzem a liberação de insulina. Tal ambiente hormonal, juntamente com fatores bioquímicos 
locais, exercem efeito estimulante sobre a enzima glicogênio fosforilase, responsável pela glicogenólise hepática e muscular. Desse modo, a taxa de glicólise a partir da glicose muscular e sangüínea é elevada e há aumento da produção do lactato, o qual, quando acumulado no músculo, pode levar à fadiga muscular.

A fadiga durante exercícios prolongados de intensidade média-alta é freqüentemente associada com a depleção de glicogênio muscular, por isso, acredita-se que a alta concentração de glicogênio muscular préexercício é essencial para o ótimo desempenho (JENTJENS et al., 2001). Estratégias de supercompensação do glicogênio muscular previamente à competição têm sido utilizadas com sucesso, assim como estratégias para poupar o glicogênio durante o exercício.

Em exercícios prolongados, outro fator que provoca a fadiga é a diminuição da concentração sangüínea de glicose, a qual é mantida durante o exercício graças aos efeitos dos hormônios glucagon e cortisol. Este último contribui por meio de três efeitos: a) diminui a utilização de glicose pelas células, fazendo com que a glicose fique acumulada no líquido extracelular; b) estimula a enzima glicogênio fosforilase a degradar o glicogênio hepático para liberação de glicose na circulação; c) estimula a gliconeogênese nas células hepáticas e renais, com uso de precursores como aminoácidos, glicerol, lactato e piruvato (NEWSHOLME \& LEECH, 1995). A disponibilização dos precursores aminoácidos e glicerol se deve também ao cortisol, que estimula o catabolismo protéico e, em sinergismo com outros hormônios, estimula também a lipólise.

A ressíntese completa de glicogênio muscular após exercício prolongado pode ocorrer dentro de 24 horas, dependendo do grau de depleção do glicogênio e da ingestão suficiente de carboidratos (PRICE ET AL., 2000;
STEENSBERG et al., 2002). Quando o carboidrato é consumido após o exercício, as concentrações de glicose e insulina no sangue aumentam. A insulina é um potente hormônio anabólico que estimula a síntese de glicogênio, gorduras e proteínas. Porém, estudo de Jentjens et al. (2001) demonstrou que a ingestão combinada de $\mathrm{CHO}$ e proteína não aumentou a síntese de glicogênio pós-exercício.

A ingestão de CHO antes, durante e após o exercício pode contribuir para o desempenho no sentido de otimizar os depósitos de glicogênio muscular e hepático e manter a normalidade da glicemia. De acordo com Liebman \& Wilkinson (1999), as pesquisas já evidenciaram que fatores como taxa de ingestão de $\mathrm{CHO}$ e taxa de esvaziamento gástrico são importantes para o desempenho durante o exercício, enquanto o tipo e a quantidade de $\mathrm{CHO}$ ingerido ao final do exercício determinam a taxa de ressíntese do glicogênio.

\section{Balanço da degradação e síntese de proteínas}

O exercício resistido representa um estímulo específico que normalmente resulta em aumento de massa muscular, indicando aumento de proteínas intracelulares como actina e miosina e, também de outras moléculas como creatina, glicogênio e água (HENRIKSSON, 1995; DESCHENES \& KRAEMER, 2002).

Ao longo do dia ocorre renovação (turnover) ininterrupta das proteínas, ou seja, elas são degradadas e sintetizadas continuamente. Em algumas condições como jejum e exercício, predomina a degradação, enquanto que no estado alimentado e repouso predomina a síntese (TRIPTON \& WOLFE, 1998). Para indivíduos sedentários ou apenas fisicamente ativos, o desejável é que degradação e síntese sejam equilibradas ao final de um determinado período, como um dia, por exemplo. Porém, atletas precisam que haja predomínio da síntese para 
que possam aumentar a massa muscular (supercompensação) e melhorar o desempenho. O exercício de resistência é um potente estímulo para o anabolismo muscular, proporcionando maior síntese em comparação com a degradação protéica. Porém, o anabolismo ocorre apenas no período de recuperação e, o consumo de carboidratos e proteínas é determinante (KOOPMAN et al., 2007).

As situações de estresse vividas ao longo do dia, inclusive de exercício, estimulam a secreção do principal estimulador do catabolismo das proteínas, o cortisol. O catabolismo ocorre na maioria dos tecidos. O resultado é disponibilidade de aminoácidos no sangue, tornando-os disponíveis para utilização, principalmente pelo fígado e rins (WAHREN \& EKBERG, 2007; AGOSTINI \& BIOLO, 2010).

A duração e intensidade dos exercícios de resistência, bem como 0 estágio do treinamento, influenciam as respostas hormonais agudas. Num estudo com treinamento de oito semanas observava-se o aumento da concentração de cortisol ao término de cada sessão, porém o aumento era menor na medida da sucessão das semanas, indicando uma atenuação do estresse imposto pela sessão de treinamento (UCHIDA et al., 2006).

As proteínas são sintetizadas a partir de estímulos que induzem adaptações musculares. Hormônios como testosterona e GH secretados durante o exercício e sono, e a insulina, secretada após as refeições, são os fatores que disparam os processos de expressão gênica e síntese protéica (HARGREAVES \& CAMERONSMITH, 2002).

Em relação ao consumo, mesmo para praticantes de exercícios de resistência, não existem evidências de que a ingestão de quantidades de proteínas superiores à necessidade estimule a incorporação do excedente nos músculos (MAUGHAN et al.,
2000). A dieta normal é constituída por 12-15\% de proteínas, em relação ao valor energético total. O treinamento com exercícios de resistência impõe maior gasto de energia e a necessidade de maior consumo absoluto de proteínas (McARDLE et al., 2011). Isso significa que, mesmo mantendo a proporção de $12-15 \%$ de proteínas, o consumo absoluto destas é maior e, normalmente, supre as necessidades.

Estudo de Koopman et al. (2007) verificou o efeito do consumo de diferentes quantidades de carboidrato em combinação com proteínas após uma sessão de exercício de resistência. Observaram que a concentração de glicose e de insulina foram maiores após o consumo da maior quantidade de carboidratos $(0,6 \mathrm{~g} / \mathrm{Kg} / \mathrm{h})$, porém, a degradação, síntese, oxidação e balanço de proteínas totais não apresentaram diferenças.

Em relação à melhor hora para 0 consumo de proteínas, foi observado num estudo de Esmarck et al. (2001) que o consumo imediatamente ao final do treinamento de resistência é mais eficiente para induzir a hipertrofia do que o consumo mais tardio, depois de três horas de recuperação.

Entre os aminoácidos constituintes das proteínas, alguns podem ser sintetizados pelo organismo e todos podem ser degradados em compostos mais simples em reações de desaminação ou transaminação. Nestas últimas pode ocorrer a síntese dos aminoácidos nãoessenciais. Nas reações de desaminação o aminoácido perde seu grupo amina, o qual pode ser convertido em amônia (NEWSHOLME \& LEECH, 1995). Esse processo é mais comum em exercícios duração prolongada, nos quais a utilização dos aminoácidos para produção de energia aumenta (MAUGHAN et al., 2000). A desaminação excessiva de aminoácidos não é desejável porque o aumento da concentração de amônia na fibra muscular e na circulação sangüínea pode ser prejudicials (SNOW et al., 
2000). A produção de amônia só não é maior nos músculos em contração porque os grupos amina são bastante utilizados para síntese dos aminoácidos alanina e glutamina, que desempenham a função de transportar os grupos amina para o fígado e rins. No primeiro destes órgãos, o grupo amina é transformado em uréia, que é relativamente inerte e pode ser excretada pelos rins sem afetar o equilíbrio ácido-básico. $\mathrm{O}$ ciclo da uréia é eficiente do ponto de vista energético, pois exige somente uma molécula de ATP para remover dois átomos de nitrogênio (RIDDELL et al., 2003). No homem adulto, a excreção da uréia chega a cerca de 30-40 g/d, mas pode aumentar duas ou três vezes se houver ingestão de dieta rica em proteínas.

Apesar dos aminoácidos servirem principalmente para síntese de proteínas e outros compostos nitrogenados, alguns deles como alanina, glutamato, aspartato, leucina, isoleucina e valina podem ser oxidados, porém em quantidades pouco significativas, mesmo durante o exercício (WAGENMAKERS, 1998). Leucina, isoleucina e valina são classificados como aminoácidos de cadeia ramificada em razão de suas estruturas, são abundantes nos músculos, são os mais utilizados como substratos energéticos nos músculos e são muito valorizados como suplementos entre os atletas. No entanto, a importância deles como combustível ocorre, principalmente, quando o glicogênio é depletado e a glicemia tende à diminuição (KREIDER et al., 1993).

A hipótese de que os aminoácidos podem ter valor ergogênico em exercícios de resistência baseia-se em evidências sobre os efeitos da arginina, histidina, lisina, metionina, ornitina e fenilalanina na estimulação da liberação do hormônio do crescimento, insulina e cortisol (KREIDER et al., 1993; LAMBERT et al., 2004). No entanto, os efeitos mais interessantes destes hormônios, especificamente os dois primeiros, aconteceriam durante a recuperação.

Num estudo de Rasmussen et al. (2000) os sujeitos realizaram duas sessões de exercícios de resistência e consumiram uma bebida contendo aminoácidos essenciais e sacarose, uma e três horas após o final do esforço. Os pesquisadores observaram que a taxa de proteólise não foi alterada, mas sim a taxa de síntese, o que proporcionou o anabolismo muscular durante a recuperação.

\section{Amônia e catabolismo}

A produção de amônia aumenta durante exercícios prolongados e intensos, em razão da desaminação de aminoácidos e da adenosina monofosfato (AMP), respectivamente (SNOW et al., 2000). A produção de amônia a partir do catabolismo AMP ocorre quando a utilização de ATP excede sua síntese e a enzima AMP desaminase é ativada (GRAHAM et al., 1990).

O catabolismo dos aminoácidos representa uma fonte de combustível para suprir a necessidade de ATP do músculo em contração. Esse combustível pode tornar-se quantitativamente mais importante com o aumento da duração do exercício e com a depleção das reservas de glicogênio (GRAHAM et al., 1997). O aumento progressivo da produção de amônia pelos músculos, observado durante o exercício de duração prolongada, pode ser um indicador de estresse metabólico muscular, já que essa produção reflete a incapacidade do músculo ativo em suprir a demanda de ATP e a dependência do catabolismo dos aminoácidos (SNOW et al., 2000).

Aumentos da concentração de amônia são absolutamente indesejáveis em quaisquer situações. Durante o exercício, a amônia pode diminuir o fluxo de intermediários na segunda metade do Ciclo de Krebs devido ao seqüestro de 2-oxoglutarato para síntese do aminoácido 
glutamato. Pode também atravessar a barreira hematoencefálica e, atingindo o córtex motor, causar descoordenação motora (NEWSHOLME \& LEECH, 1995). Durante a recuperação, a produção de amônia diminui, enquanto a remoção pelo fígado e rins continua elevada, fazendo com que a concentração retorne ao basal dentro de aproximadamente 20 minutos.

Devido a isto, avaliações da concentração de amônia durante o exercício e recuperação podem indicar a necessidade do consumo de carboidratos, tanto para a manutenção do exercício como para inibir o catabolismo e estimular 0 anabolismo no período de recuperação.

\section{Processos anabólicos pós-exercício}

A insulina tem efeito especialmente importante no metabolismo dos carboidratos, gorduras e proteínas. Após uma refeição, quando a glicemia aumenta, a insulina estimula 0 transporte de glicose para o interior das fibras musculares em quantidades muito maiores do que a necessária para produção de energia. Nas fibras musculares e no fígado, o hormônio estimula também o armazenamento de glicogênio. Nos intervalos entre uma refeição e outra, nas células hepáticas, a enzima fosforilase é ativada e despolimeriza o glicogênio em glicose, liberando-a para a corrente sanguínea.

Os indivíduos em geral, quando aderem a um programa de exercício resistido, visam à estética corporal, ou seja, o aumento de massa muscular assim como o aumento de força, a custa de treinamento associado a dietas hiperprotéicas, hipercalóricas e suplementação. Os processos de síntese protéica e ressíntese do glicogênio dependem da disponibilidade dos substratos e de um ambiente hormonal favorável que promova a necessária estimulação (Figura 1).

Oliveira et al. (2006) analisaram 16 voluntários, divididos em dois grupos, com dieta hiperprotéica (HP, 4g/kg/d) e normoprotéica (NP, $2 \mathrm{~g} / \mathrm{kg} / \mathrm{d}$ ). O treinamento consistiu em exercícios com pesos durante 8 semanas, 3 vezes por semana. Os resultados mais significativos observados foram que a ingestão da dieta HP provocou maior aumento da massa muscular e força em comparação com a dieta normoprotéica. Por outro lado, o grupo NP apresentou diminuição de $18,1 \%$ na concentração de cortisol, enquanto o grupo de HP apresentou aumento de 33,6\%.

Num estudo de Thyfault e Hulver (2004), foram examinados os efeitos da suplementação de carboidrato líquido sobre anabolismo após exercícios de intensidade alta. Nove homens treinados consumiram carboidrato ou placebo, dez minutos antes e imediatamente após duas sessões de exercício de resistência. Observou-se diferença significativa na concentração de insulina imediatamente após o exercício e uma hora e meia após o exercício. As concentrações de cortisol, amônia e glicose não foram significativamente diferentes entre os tratamentos. Os autores concluíram que, apesar dos indicadores indiretos de degradação protéica não sofrerem alterações com a ingestão do carboidrato, a maior concentração de insulina é um forte indicativo do favorecimento do anabolismo após o exercício.

Em exercícios contínuos de duração prolongada e intermitentes de intensidade alta com duração próxima de uma hora, a redução no desempenho pode ser conseqüência da diminuição do glicogênio muscular, havendo decréscimo da produção de força isocinética, força isométrica e fraqueza muscular. O consumo de suplementos de carboidratos antes e durante exercícios resistidos pode reduzir a depleção do glicogênio muscular e proporcionar a manutenção do desempenho em alto nível por períodos mais prolongados (HAFF et al., 2003). 
Consumo de CHO

A

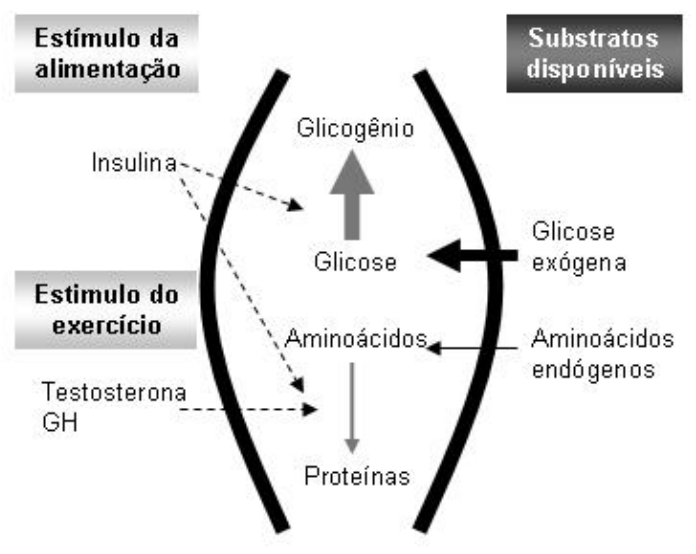

Consumo de CHO e proteína

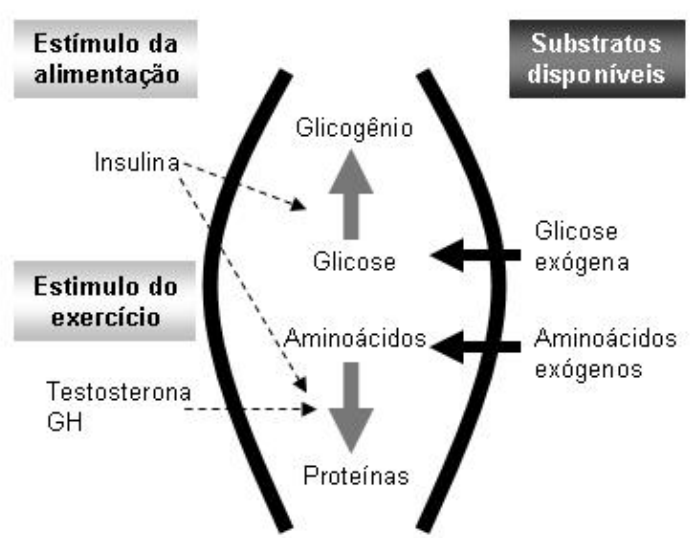

Figura 1. Representação esquemática da ressíntese do glicogênio e síntese de proteínas após exercício resistido e consumo de carboidrato (CHO; A) e carboidrato e proteína (B). Os hormônios testosterona e do crescimento (GH) são secretados durante o exercício e estimulam (setas tracejadas) a síntese protéica durante a recuperação. A insulina é secretada após o consumo de carboidrato e estimula (setas tracejadas) a ressíntese do glicogênio e síntese protéica durante a recuperação. A principal diferença está na disponibilidade de aminoácidos exógenos após o consumo de proteínas, o que permitiria maior taxa de síntese protéica. Dessa forma, assim como para a ressíntese do glicogênio, a síntese de proteínas seria proporcional à disponibilidade de precursores.

Chandler et al. (2003) estudaram a ingestão de bebida contendo carboidrato imediatamente antes e duas horas após uma série de exercício resistido. Observaram aumento significativo na concentração de insulina em comparação à bebida placebo. Este aumento de insulina cria um ambiente hormonal favorável ao anabolismo, o que compreende a ressíntese de glicogênio, síntese protéica e hipertrofia muscular. A coingestão de carboidratos e proteínas pode ter efeito principalmente na síntese protéica, já que, além do estimulo da insulina proporcionado pelos carboidratos, os aminoácidos também são disponibilidados (HOWARTH et al., 2009).

Há estudos demonstrando que o consumo de carboidratos pós-exercício é suficiente para estimular o anabolismo muscular. Børsheim et al. (2004) demonstraram que a ingestão de $100 \mathrm{~g}$ de carboidratos após exercício de resistência tem efeito positivo no balanço protéico, porém o efeito é menor e mais tardio em comparação ao consumo de aminoácidos.

Uma alternativa no fornecimento de nutrientes são as proteínas ou aminoácidos, ingeridos isoladamente ou em composição com carboidratos. Num estudo de Esmarck et al. (2001), verificou-se que o consumo de suplemento de proteína logo após exercício resistido é importante para o desenvolvimento da hipertrofia muscular em homens idosos ativos. Por outro lado, Miller et al. (2003) demonstraram não haver diferenças significativas na secreção hormonal e anabolismo após a ingestão de aminoácidos ou carboidratos isoladamente ou combinação de ambos. De acordo com sugestão dos autores, a quantidade ingerida de um ou outro poderia talvez exercer influência.

Contrariamente, num estudo de Bird et al. (2006) sobre os efeitos independentes e combinados da ingestão de carboidrato líquido e aminoácidos essenciais na secreção hormonal e processos metabólicos musculares após treinamento resistido em homens destreinados, verificou-se que o consumo combinado diminuiu a degradação e aumentou o anabolismo muscular mais que o consumo independente. 


\section{CONFLITO DE INTERESSE}

Os autores declaram não haver qualquer potencial conflito de interesse que possa interferir na imparcialidade deste trabalho científico.

\section{CONCLUSÃO}

Podemos verificar que as alternativas de consumo de carboidratos e proteínas ou suplementação pós-exercício para o estímulo do anabolismo são eficientes, porém encontram-se variações nos resultados. As quantidades de carboidratos e proteínas ou aminoácidos são também determinantes para proporcionar um ambiente hormonal favorável para sua utilização nos processos de ressíntese do glicogênio e síntese protéica. Os resultados dos estudos já realizados estão longe de um consenso, porém podemos considerar que a secreção e concentração de insulina desempenham papel chave no processo anabólico pós-exercício. Estudos com diferentes combinações e quantidades de nutrientes são necessários, principalmente com a avaliação direta dos processos de ressíntese do glicogênio e síntese protéica.

\section{REFERÊNCIAS}

Agostini F, Biolo G. Effect of physical activity on glutamine metabolism. Curr Opin Clin Nutr Metab Care. 2010;13(1):58-64. http://dx.doi.org/10.1097/MCO.0b013e328332f946

Al Mulla N, Simonsen L, Bülow J. Post-exercise adipose tissue and skeletal muscle lipid metabolism in humans: the effects of exercise intensity. J Physiol. 2000;542.3:919-28. http://dx.doi.org/10.1111/i.1469-

\subsubsection{9.x}

Bird SP, Tarpenning KM, Marino FE. Independent and combined effects of liquid carbohydrate/essential amino acid ingestion on hormonal and muscular adaptation following resistance training in untrained men. Eur J Appl Physiol. 2006;97(2):225-38. http://dx.doi.org/10.1007/s00421-006-0173-1

Børsheim E, Cree MG, Tipton KD, Elliott TA, Aarsland A, Wolfe RR. Effect of carbohydrate intake on net muscle protein synthesis during recovery from resistance exercise. J Appl Physiol. 2004;96(2):674-8.

http://dx.doi.org/10.1152/japplphysiol.00333.2003

Chandler RM, Byrne HK, Patterson JG, IVy JL. Dietary supplements affect the anabolic hormones after weight-training exercise. J Appl Physiol. 2003;76:839-45.

Coyle EF. Physical activity as a metabolic stressor. Am J Clin Nutr. 2000;72:512S-20S.

Deschenes MR, Kraemer WJ. Performance and physiologic adaptations to resistance training. Am J Phys Med Rehabil. 2002;81:S3-S16. http://dx.doi.org/10.1097/00002060-200211001$\underline{00003}$

Esmarck B, Andersen JL, Olsen S, Richter EA, Mizuno M, Kjaer M. Timing of postexercise protein intake is important for muscle hypertrophy with resistance training in elderly humans. J Physiol. 2001;535.1:301-11.

http://dx.doi.org/10.1111/i.1469-

7793.2001.00301.x

Graham TE, Bangsbo J, Gollnick PD, Juel C, Saltin B. Ammonia metabolism during intense dynamic exercise and recovery in humans. Am J Physiol. 1990;259:E170-E176.

Graham TE, Turcotte LP, Kiens B, Richter EA. Effect of endurance training on ammonia and amino acid metabolism in humans. Med Sci Sports Exerc. 1997;29:646-53. http://dx.doi.org/10.1097/00005768-19970500000010

Haff GG, Lehmkuhl MJ, McCoy LB, Stone MH. Carbohydrate supplementation and resistance training. J Strength Cond Res. 2003;17:187-196. http://dx.doi.org/10.1519/00124278-200302000$\underline{00029}$

Hargreaves M, Cameron-Smith D. Exercise, diet, and skeletal muscle gene expression. Med Sci Sports Exerc. 2002;34:1505-8. http://dx.doi.org/10.1097/00005768-20020900000017

Henriksson J. Effect of training and nutrition on the development of skeletal muscle. J Sports Sci. 1995;13:S25-S30.

http://dx.doi.org/10.1080/02640419508732273

Howarth KR, Moreau NA, Phillips SM, Gibala MJ. Coingestion of protein with carbohydrate during recovery from endurance exercise stimulates skeletal muscle protein synthesis in humans. J Appl Physiol. 2009;106(4):1394-402. http://dx.doi.org/10.1152/japplphysiol.90333.2008 
Jentjens RLPG, van Loon LJC, Mann CH, Wagenmakers AJM, Jeukendrup AE. Addition of protein and amino acids to carbohydrates does not enhance postexercise muscle glycogen synthesis. J Appl Physiol. 2001;91:839-46.

Koopman R, Beelen M, Stellingwerff T, Pennings $B$, Saris $W H$, Kies AK, Kuipers $H$, van Loon LJ. Coingestion of carbohydrate with protein does not further augment postexercise muscle protein synthesis. Am J Physiol Endocrinol Metab. 2007;293(3):E833-42.

http://dx.doi.org/10.1152/ajpendo.00135.2007

Koopman R, Saris WH, Wagenmakers AJ, van Loon LJ. Nutritional interventions to promote postexercise muscle protein synthesis. Sports Med. 2007;37(10):895-906.

http://dx.doi.org/10.2165/00007256-200737100$\underline{00005}$

Kreider RB, Miriel V, Bertun E. Amino acid supplementation and exercise performance. Sports Med. 1993;16:190-209. http://dx.doi.org/10.2165/00007256-199316030$\underline{00004}$

Lambert CP, Frank LL, Evans WJ. Macronutrient considerations for the sport of bodybuilding. Sports Med. 2004;34:317-27. http://dx.doi.org/10.2165/00007256-200434050$\underline{00004}$

Liebman M, Wilkinson JG. Metabolismo de carboidratos e condicionamento físico. In: Wolinsky I \& Hickson Jr J. Nutrição no exercício e no esporte. 2ed. São Paulo: Roca; 1999.

Maughan RJ, Gleeson M, Greenhaff PL. Bioquímica do exercício e treinamento. São Paulo: Manole; 2000.

McArdle WD, Katch FI, Katch VL. Fisiologia do exercício: energia, nutrição e desempenho Humano. 7ed. Rio de Janeiro: GuanabaraKoogan; 2011.

Miller SL, Tripton KD, Chinkes DL, Wolfe SE, Wolfe RR. Independent and combined effects of amino acids and glucose after resistance exercise. Med Sci Sports Exerc. 2003;35:449-55. http://dx.doi.org/10.1249/01.MSS.0000053910.63 $\underline{105.45}$

Newsholme EA, Leech AR. Biochemistry for the medical sciences. New York: John Wiley \& Sons; 1995.

Oliveira PV, Baptista L, Moreira F, Lancha Junior $\mathrm{AH}$. Correlação entre a suplementação de proteína e carboidrato e variáveis antropométricas e de força em indivíduos submetidos a um programa de treinamento com pesos. Rev Bras
Med

Esporte.

2006;12:51-5.

http://dx.doi.org/10.1590/S1517$\underline{86922006000100010}$

Price TB, Laurent D, Petersen KF, Rothman DL, Shulman GI. Glycogen loading alters muscle glycogen resynthesis after exercise. J Appl Physiol. 2000;88:698-704.

Rasmussen BB, Tripton KD, Miller SL, Wolf SE, Wolfe RR. An oral essential amino acidcarbohydrate supplement enhances muscle protein anabolism after resistance exercise. J Appl Physiol. 2000;88:386-92.

Riddell MC, Partington SL, Stupka N, Armstrong D, Rennie C, Tarnopolsky MA. Substrate utilization during exercise performed with and without glucose ingestion in female and male endurance trained athletes. Int J Sport Nutr Exerc Metab. 2003;13(4):407-21.

Smilios I, Pilianidis T, Karamouzis M, Tokmakidis SP. Hormonal responses after various resistance exercise protocols. Med Sci Sports Exerc. 2002;35(4):644-54.

http://dx.doi.org/10.1249/01.MSS.0000058366.04 460.5F

Snow RJ, Carey MF, Stathis CG, Febbraio MA, Hargreaves $M$. Effect of carbohydrate ingestion on ammonia metabolism during exercise in humans. J Appl Physiol. 2000;88:1576-80.

Steensberg A, van Hall G, Keller C, Osada T, Schjerling $\mathrm{P}$, Pedersen BK et al. Muscle glycogen content and glucose uptake during exercise in humans: influence of prior exercise and dietary manipulation. J Physiol. 2002;541.1:273-81. http://dx.doi.org/10.1113/jphysiol.2001.015594

Thyfault JP, Hulver MW. Effects of liquid carbohydrate ingestion on markers of anabolism following high-intensity resistance exercise. J Strength Cond Res. 2004;18:174-9. http://dx.doi.org/10.1519/00124278-20040200000026

Tripton KD, Wolfe RR. Exercise-induced changes in protein metabolism. Acta Physiol Scand. 1998;162:377-87. http://dx.doi.org/10.1046/j.1365201X.1998.00306.X

Uchida MC, Aoki MS, Navarro F, Tessutti VD, Bacurau RFP. Efeito de diferentes protocolos de treinamento de força sobre parâmetros morfofuncionais, hormonais e imunológicos. Rev Bras Med Esporte. 2006;12:21-26.

Wagenmakers AJ. Muscle amino acid metabolism at rest and during exercise: role in human physiology and metabolism. Exerc Sport Sci Rev. 1998;26:287-314. 
http://dx.doi.org/10.1249/00003677-199800260-

$\underline{00013}$

Wahren J, Ekberg K. Splanchnic regulation of glucose production. Annu Rev Nutr. 2007;27:32945.

http://dx.doi.org/10.1146/annurev.nutr.27.061406. $\underline{093806}$

Wolfe RR. Protein supplements and exercise. Am J Clin Nutr. 2000;72:551S-7S. 